Original Investigation

\title{
Awareness and Perception Regarding Health Insurance among Community people in a Municipality: A Cross Sectional Study
}

\author{
Bharat Ram Dhungana ${ }^{1 *}$, Shree Shyam Giri², Shambhu Prasasd Kushwaha ${ }^{3}$, Dammar Kumari Khanal ${ }^{4}$, \\ Binod Kumar Yadav5,6
}

${ }^{1}$ Faculty of Management Studies, Pokhara University, Pokhara, Nepal, ${ }^{2}$ College of Nursing, Sinha Health Foundation, Janakpur, Nepal. ${ }^{3}$ District Health Office, Dhanusha, Janakpur, Nepal. ${ }^{4}$ National Health Training Centre, Teku, Kathmandu, Nepal. ${ }^{5}$ Madhesh Institute of Health Sciences, Province-2, Janakpur, Nepal, ${ }^{6}$ Department of Biochemistry, Maharajgung Medical Campus, Institute of Medicine, Kathmandu, Nepal.

\section{ARTICLE INFO \\ Received: 17 March 2021 \\ Revised: 11 May 2021 \\ Accepted: 07 June 2021 \\ *Correspondence: Dr. Bharat Ram Dhungana Faculty of Management studies, Pokhara University, Pokhara, Nepal. \\ E-mail: dhunganabharat.pu@gmail.com \\ Dhungana BR, Giri SS, Kushwahe SP, Khanal DK, Yadav BK. \\ Awareness and Perception \\ Regarding Health Insurance among Community People in a Municipality: A Cross Sectional Study. MedS, J. Med. Sci. 2021}

1(1): 76-82

\begin{abstract}
ABSTARCT
INTRODUCTION: Health insurance program is a social protection program of the government of Nepal, which aims to enable its citizens to have access to quality health care services without placing financial burden on them. There was insufficient knowledge and awareness of the health insurance activities. Insured persons have complained of poor attitude and behaviour of service providers operating in the health insurance scheme. The aim of this study was to investigate the awareness and perception regarding health insurance among community people in a municipality. MATERIALS AND METHODS: A crosssectional survey assessing awareness and perception of community people on health insurance was conducted using a structured questionnaire in Bardibas municipality of Mahottari district of Nepal during the month of August 2019 to October 2019. A total of 422 sample were selected by use of simple random sampling technique and face-to-face interview was conducted using the structured questionnaire. Multivariable logistic regression model was applied to test the effects of independent variables after adjusted potential confounders. A $p$-value $\leq 0.05$ was considered statistically significant. RESULTS: Participants who were from age group of less than 30 years [aOR 2.82; 95\% CI (1.46-5.47)] of male gender [aOR 2.03; 95\% CI (1.13-3.66)], from upper caste [aOR 6.22; 95\% CI (2.97-13.0)], and had higher secondary education level and above [aOR 4.66; 95\% CI (2.81-7.74)] were likely to have adequate level of awareness than counterparts. Likewise, participants who were married [aOR 3.46; 95\% CI (1.577.63)], had higher secondary education level and above [aOR 4.74; 95\% CI (2.857.87)], and involved in services or business [aOR 8.67; 95\% CI (3.54-21.23)], were more likely to have satisfactory perception on health insurance. CONCLUSIONS: Education level and occupation has influence on the level of awareness and perception of health insurance. Therefore, awareness programme on health insurance need to be implemented through mass media campaign.
\end{abstract}

Keywords: Awareness, health insurance, perception.

\section{INTRODUCTION}

Monitoring health inequalities is essential for achieving universal health coverage as it enables populations that were left behind, to be identified and helps to form equity-oriented policies, programmes and practices [1]. Nepal's constitution of 2015 addresses health as a fundamental right, stating that every citizen shall have the right to free basic health services from the State, and no one shall be deprived of emergency health services [2]. But in reality, most of the people are still not getting qualitative and affordable health services from the government and public health institutions [3].

A health insurance scheme has been defined as an arrangement in which contributions 
are made by or on behalf of individuals or groups (members) to a purchasing institution which is responsible for purchasing covered services from providers on behalf of the members of the scheme [4]. Health insurance is associated with higher treatment likelihood and mitigates socio-economic and regional disparities in health care treatment. The insurance scheme aims to ensure universal health coverage by increasing access to and utilization of quality health services $[5,6]$.

Health Insurance Board (HIB) of Nepal is a government authority, formulated to plan, manage and operate health insurance services as per the mandate of Nepal Health Insurance Act and its regulation. HIB was formed following the enactment of the Nepal Health Insurance Act 2017. Health insurance program is a social protection program of the government of Nepal that aims to enable its citizens to have access to quality health care services without placing financial burden on

\section{MATERIALS AND METHODS}

Study design and setting

A cross-sectional survey assessing awareness and perception of community people on health insurance was conducted using a structured questionnaire in Bardibas municipality of Mahottari district of Nepal in the month of August 2019 to October 2019. The municipality is located in Terai region of Province-2 with a population of 173,924 where majority population speak Nepali.

\section{Sample size and sampling}

The sample size was calculated using a formula for a single proportion as follows: $\mathrm{n}=\mathrm{Z} 2 \mathrm{pq} / \mathrm{e} 2$ where, $\mathrm{n}$ is the minimum desired sample size, $Z=1.96$ is the standard normal deviate at $5 \%$ level of significance, since previous literature on prevalence of health insurance at the time of data collection was unknown, therefore $\mathrm{p}$ was taken as $50 \%$ to account for maximum sample and e is the precision taken as $5 \%$. This yields a sample of 384 participants. Additional, $10 \%$ was considered for potential nonresponse. Therefore, total sample calculated was 422. Hence, we covered 425 samples. Simple random sampling technique was used to select the households in the municipality. There were 27 wards in Bardibas municipality. Out of 27, three wards were selected randomly. them. The strategy of HIB is to enhance the participation of communities towards health insurance program by providing special protection to the poor and marginalized and extend coordination and cooperation with government and non-government service provider health institutions for gradual expansion of health insurance program throughout the country $[7,8]$.

There was insufficient knowledge and awareness of health insurance activities. Insured-persons have complained of poor attitude and behaviour of service providers operating in the health insurance scheme. Expensive health care discourages people to use health services, generating prolonged or worsened health problems $[9,10]$. Thus, health insurance is important in developing countries like Nepal because it diversifies financial risk, raise income levels and can offer large welfare gains [11]. The study aims to investigate awareness and perception regarding health insurance among community people in a municipality.

In three wards, again households were selected by the use of simple random sampling methods. Head of the households were selected for the interview till 425 were interviewed by probability proportional to size (PPS) methods. The participants who were mentally ill or had any disability were excluded from this study.

Data collection

A face-to-face interview was conducted using structured questionnaire. The questionnaire had two sections. Baseline questionnaire included the demographic variables like age, sex, educational status, marital status, occupation, property ownership and access to financial institution in the first section. The second section consisted of assessment of awareness and perception of the participants.

Assessment of awareness and perception were based on following parameters:
A. Awareness on health insurance of participants was assessed based on following questions.
1. Have you ever heard about health insurance.
2. Have you ever heard about the health insurance scheme.


3. Are you eligible to any kinds of health insurance.

4. Do you know your benefit package.

5. Do you know how to use your health insurance.

6. Financial Protection Against Illness.

7. The coverage of policy.

8. Where to contact for health insurance.

9. How to get claim on health insurance.

10. The maximum number of claims in a year.

B. Perception on health insurance of participants was assessed based on following questions.

1. Health insurance policy is a worth investment.

2. Health insurance could prevent financial hardship if you get sick.

3. Health insurance can improve health care delivery system in your family.

4. Health insurance provide a sense of security regarding medical care to you and to your family.

5. It will be good to take a health insurance at a younger age.

6. Taking health insurance is good for you.

7. Health insurance is essential for each family.

8. Health insurance policy is a right instrument to mitigate health related risks.

9. There is easy process for acquiring health insurance policy.

10. I am fully satisfied with health insurance policy.

One score ( 0 or 1$)$ was assigned for each parameter by asking the participants for their awareness and perception regarding health insurance.

For awareness, zero was assigned when response was "No" and score 1 was assigned when the response was "Yes". Similarly, the score was assigned for each of the parameter of perception. Zero was assigned, if there the response was "disagree" and one, if the response was "agree". As the score of these parameters ranged from 0 to 1 , hence the total possible maximum score was 10 for each awareness and perception. The sum of scores for all the parameters for each participant was calculated and taken as level of awareness and perception.

The median for awareness and perception was calculated. The total scores for each participants were then split at the median. Accordingly level of awareness on health insurance was categorized into
"Adequate" and "Inadequate". If the responses were equal or more than the median score, the participant's awareness was considered "Adequate". If the responses were less than the median, the participant's awareness was considered "Inadequate". Similarly, Perception was considered "Satisfactory" for equal and more than median score and "Unsatisfactory" for score less than the median.

Awareness in terms of adequate and inadequate category and perception in terms of satisfactory and unsatisfactory category was taken as the dependent variable. Age, education, caste, occupation, marital status, property ownership and access to financial institution were taken as independent variables.

Age of participants was categorized as $<30$ years, $30-40$ years and $>40$ years. Education was recorded as primary/secondary vs higher secondary and above. Ethnicity was based on the caste system in Nepal and was divided into three major groups based on available literature and similarities between the caste/ethnic groups: upper caste (Brahmin, Chhetri), Janajati and Dalit. Occupation was divided into two category as Service/Business vs Agriculture. Property ownership and access to financial institution were categorized as Yes and No.

Ethical approval from Institutional Review Committee of Janaki Medical College and also written approval letter was obtained from municipality Office, Bardibas. Participants provided consent for themselves before an interview. Personal identifiers were removed before data analysis.

\section{Statistical considerations}

Frequencies and percentages were used to present the categorical variables. The association between independent variables and the level of awareness and perception were assessed using Chi-square $(\chi 2)$ test in univariate analysis. Then, the effect of each of the independent variables were adjusted in a multivariable logistic regression model. A $p$-value $\leq$ 0.05 was considered statistically significant. Data was analysed using statistical package for social sciences (SPSS) version 23.0 for window 


\section{RESULTS}

Socio-demographic characteristics of study participants

About three fourth of them $(74.4 \%)$ were of less than 30 years of age and $77.2 \%$ were male. $60.0 \%$ of them had higher secondary and above level of education. About half of them $(50.6 \%)$ were of upper caste and $55.5 \%$ were involved in agriculture. Majority of them $(82.8 \%)$ were married. More than half $(62.2 \%)$ of the participants had no property ownership whereas (61.4\%) had access to financial institution (Table 1).

Table 2 presents the distinctions in awareness and perceptions of participants by socio-demographic characteristics. The crude odds ratio shows all the socio-demographic variables are associated with adequate awareness on health insurance except the marital status and property ownership. However, level of education, occupation, marital status, and access to financial institutions are associated with satisfactory level of perception on health insurance.

The results of multivariable logistic regression analysis are shown in Table 3. Participants who were from age group of less than 30 years were more likely to had satisfactory awareness on health insurance [aOR 2.82; 95\% CI (1.46-5.47)] than the age group 30-40 years and more than 40 years of age.

Participants of male gender [aOR 2.03; 95\% CI (1.13-3.66)] and from upper caste[aOR 6.22; 95\% CI (2.97-13.0)], had education level higher secondary and above [aOR 4.66; 95\% CI (2.817.74)] were likely to had adequate level of awareness than counterpart of female, dalit or janajati, and primary to secondary level of education respectively. On the other hand, participants who were married [aOR 3.46; 95\% CI (1.57-7.63)], had education level higher secondary and above [aOR 4.74; 95\% CI (2.85-7.87)] and were involved in services or business [aOR 8.67; 95\% CI (3.54-21.23)] were more likely to have satisfactory perception on health insurance.
Table 1I Socio-demographic characteristics of study participants

\begin{tabular}{lll}
\hline Characteristics & $\begin{array}{l}\text { Total } \\
(\mathrm{N}=425)\end{array}$ & $\begin{array}{l}\text { Percentage } \\
(\%)\end{array}$ \\
\hline
\end{tabular}

\begin{tabular}{lcc}
\hline Age (years) & & \\
$<30$ & 152 & 35.8 \\
$30-40$ & 163 & 38.4 \\
$>40$ & 110 & 25.9
\end{tabular}

\section{Gender}

$\begin{array}{lll}\text { Male } & 329 & 77.2\end{array}$

$\begin{array}{lll}\text { Female } & 97 & 22.8\end{array}$

Caste/Ethnicity

Upper Caste $215 \quad 50.6$

$\begin{array}{lll}\text { Janajati } & 145 & 34.1\end{array}$

Dalit $\quad 65 \quad 15.3$

Marital Status

$\begin{array}{lll}\text { Married } & 352 & 82.8\end{array}$

$\begin{array}{lll}\text { Unmarried } & 73 & 17.2\end{array}$

Educational Level

Higher secondary \& above $\quad 255 \quad 60.0$

$\begin{array}{lll}\text { Primary-secondary } & 170 & 40.0\end{array}$

Hiigher

\section{Occupation}

Service/Business $\quad 189 \quad 44.5$

$\begin{array}{lll}\text { Agriculture } & 236 & 55.5\end{array}$

Property ownership

$\begin{array}{lll}\text { Yes } & 159 & 37.4\end{array}$

$\begin{array}{lll}\text { No } & 266 & 62.6\end{array}$

Access to Financial Institution

Yes

$261 \quad 61.4$

$\mathrm{No}$

164

38.6 


\begin{tabular}{|c|c|c|c|c|c|c|c|c|}
\hline \multicolumn{6}{|c|}{$\begin{array}{l}\text { Table 2| Association of Awareness and Perception on health insurance } \\
\text { Level of Awareness on health Insurance }\end{array}$} & \multicolumn{3}{|c|}{ Level of Perception on Health Insurance } \\
\hline \multicolumn{2}{|l|}{ Characteristics } & $\begin{array}{l}\text { Adequate } \\
(\mathrm{n}=256)(\%)\end{array}$ & \multicolumn{2}{|l|}{$\begin{array}{l}\text { COR } \\
(95 \% \mathrm{CI})^{*}\end{array}$} & $\begin{array}{l}\mathrm{p}- \\
\text { value }\end{array}$ & $\begin{array}{l}\text { Satisfactory } \\
(n=199)(\%)\end{array}$ & $\operatorname{COR}(95 \% \mathrm{CI})^{* *}$ & $\begin{array}{l}\mathrm{p} \text { - } \\
\text { value }\end{array}$ \\
\hline \multicolumn{9}{|l|}{ Age (years) } \\
\hline \multicolumn{2}{|l|}{$<30$} & $99(65.1)$ & \multicolumn{2}{|c|}{$2.08(1.26-3.44)$} & 0.004 & $83(54.6)$ & $0.69(0.42-1.13)$ & 0.144 \\
\hline $30-40$ & & $105(64.4)$ & \multicolumn{2}{|c|}{ 2.01(1.23-3.30) } & 0.005 & $93(57.1)$ & $0.62(0.38-1.02)$ & 0.060 \\
\hline$>40$ & & $52(47.3)$ & \multicolumn{2}{|l|}{1.00} & & $50(45.5)$ & 1.00 & \\
\hline \multicolumn{9}{|l|}{ Gender } \\
\hline Male & & $210(64.0)$ & \multicolumn{2}{|c|}{ 1.97(1.24-3.11) } & 0.004 & 172(52.4) & $1.13(0.72-1.79)$ & \multirow[t]{2}{*}{0.575} \\
\hline Female & & $46(47.4)$ & \multicolumn{2}{|l|}{1.00} & & $54(55.7)$ & 1.00 & \\
\hline \multicolumn{9}{|l|}{ Caste/Ethnicity } \\
\hline Upper Caste & & $158(73.5)$ & \multicolumn{2}{|c|}{$7.23(3.88-13.48)$} & $<0.0001$ & 107(49.8) & $1.72(0.97-3.05)$ & 0.061 \\
\hline Janajati & & $80(55.2)$ & \multicolumn{2}{|c|}{$3.21(1.70-6.06)$} & $<0.0001$ & $78(53.8)$ & $1.46(0.80-2.67)$ & \multirow[t]{2}{*}{0.211} \\
\hline Dalit & & $18(27.7)$ & \multicolumn{2}{|l|}{1.00} & & $41(63.1)$ & 1.00 & \\
\hline \multicolumn{9}{|l|}{ Marital Status } \\
\hline Married & & $214(60.8)$ & $1.14(0.68$ & $90)$ & 0.605 & $204(58.0)$ & $3.19(1.85-5.49)$ & $<0.0001$ \\
\hline Unmarried & & $42(57.5)$ & 1.00 & & & $22(30.1)$ & 1.00 & \\
\hline Educational Level & & & & & & & & \\
\hline Higher secondary \& a & ove & 192(75.3) & $5.04(3.31$ & .69) & $<0.0001$ & $103(40.4)$ & $3.86(2.54-5.87)$ & $<0.0001$ \\
\hline Primary-secondary & & $64(37.6)$ & 1.00 & & & $123(72.4)$ & 1.00 & \\
\hline Occupation & & & & & & & & \\
\hline Service/Business & & $153(81.0)$ & $5.48(3.51$ & $.56)$ & $<0.0001$ & $52(27.5)$ & 7.39(4.80-11.38) & $<0.0001$ \\
\hline Agriculture & & $103(43.6)$ & 1.00 & & & $174(73.7)$ & 1.00 & \\
\hline Property ownership & & & & & & & & \\
\hline Yes & & $104(65.4)$ & $1.41(0.94$ & .13) & 0.093 & $76(47.8)$ & $1.41(0.95-2.09)$ & 0.086 \\
\hline No & & 152(57.1) & 1.00 & & & $150(56.4)$ & 1.00 & \\
\hline Access to Financial Ir & titut & & & & & & & \\
\hline Yes & & $136(82.9)$ & $5.70(3.55$ & .16) & $<0.0001$ & $58(35.4)$ & $3.30(2.19-4.96)$ & $<0.0001$ \\
\hline No & & $120(46.0)$ & 1.00 & & & $168(64.4)$ & 1.00 & \\
\hline Table 3| Awareness & nd pe & rception on $\mathrm{h}$ & th insura & ce by 1 & nultivariab & ble logistic reg & ression model & \\
\hline Characteristics & Cate & gory & & Leve & of Aware & eness & Level of Percepti & \\
\hline & & & & $\begin{array}{l}\text { aOR } \\
\text { (Satis } \\
\text { Unsa }\end{array}$ & $\begin{array}{l}95 \% \mathrm{CI}) \\
\text { factory vs } \\
\text { isfactory) }\end{array}$ & p-value & $\begin{array}{c}\text { aOR }(95 \% \mathrm{CI}) \\
\text { (Adequate vs } \\
\text { Inadequate) }\end{array}$ & $p$-value \\
\hline Age (years) & $<30$ & & & 2.82 & $1.46-5.47)$ & 0.002 & - & - \\
\hline & $30-$ & & & 1.20 & $0.65-2.22)$ & 0.546 & - & - \\
\hline & $>40$ & & & 1.00 & & & - & - \\
\hline Gender & Ma & & & 2.03 & 1.13-3.66) & 0.017 & - & - \\
\hline & Fen & nale & & 1.00 & & & - & - \\
\hline Caste/Ethnicity & $\mathrm{Up}$ & ber Caste & & 6.22 & 2.97-13.00) & $<0.0001$ & - & - \\
\hline & Jan & ajati & & 1.50 & $0.86-2.62)$ & 0.150 & - & - \\
\hline & Dal & & & 1.00 & & - & - & - \\
\hline Marital Status & Mar & ried & & - & & - & $3.46(1.57-7.63)$ & 0.002 \\
\hline & Unn & tarried & & - & & - & 1.00 & - \\
\hline Educational Level & Hig & ter secondary & \& above & 4.66 & 2.81-7.74) & $<0.0001$ & $4.74(2.85-7.87)$ & $<0.0001$ \\
\hline & Prin & lary-secondar & & 1.00 & & - & 1.00 & \\
\hline Occupation & Serv & ice/Business & & 2.84 & $1.35-5.98)$ & 0.006 & 8.67(3.54-21.23) & $<0.0001$ \\
\hline & Agr & culture & & 1.00 & & - & 1.00 & - \\
\hline Access to Financial & Yes & & & 3.10 & 1.35-7.09) & 0.007 & - & - \\
\hline Institution & No & & & 1.00 & & - & - & - \\
\hline Adjusted for significe & it var & iables associa & d with a & reness & and per & ion. & & \\
\hline
\end{tabular}




\section{DISCUSSION}

Health insurance is an alternative source of health care financing. It has been implemented as part of health reform programmes and strategies aimed towards providing effective and efficient health care for citizens, most especially for the poor and vulnerable [12]. It is a social protection programme that aims to provide an effective quality health care services without placing financial burden to the people, especially marginalized and vulnerable people. Health insurance policy has become an important instrument to mitigate health inequalities in the developing world [13].

This study indicated that all the socio-demographic variables were associated with adequate awareness on health insurance except the marital status and property ownership. Likewise, the level of education, occupation, marital status and access to financial institutions were associated with satisfactory level of perception on health insurance. Adequate level of awareness on health insurance was found higher in the participants of age group less than 30 years, married, upper caste and having higher education and above. Similarly, the level of perception on health insurance was found higher in the participants who were married, higher education and above, and had service/business as occupation.

These result were consistent with studies conducted by other researchers [14-17]. The awareness regarding health insurance was found good, which shows the positive acceptance of social health Insurance scheme by community. Insurance agent and female community health volunteers (FCHV) seemed to have played an important role in dissemination of information [14]. A high satisfaction rate was found in health insurance

\section{ADDITIONAL INFORMATION AND DECLARATIONS}

Acknowledgment: We are thankful to all the participants of Bardibas municipality.

Funding: The authors received no funding for this work.

Competing Interests: The authors declare no competing interests. scheme. Marital status, general knowledge and awareness of contributions positively influenced client's satisfaction [15]. Majority of the families were aware of the health insurance policy scheme and the most frequent source of knowledge was their friends/ family members followed by insurance service providers [16]. The socioeconomic factors, individual's product perception and personality traits induced health insurance policy subscription [17].

An individual with a low income may be unable to afford preventive or curative care in different disease condition, which may result in the worsening of his or her state of health [18]. Most health care in Nepal is paid out-of-pocket, often incurring significant portion of the income of individual household leading to catastrophic health expenditure [19]. The health insurance policy came as an effort to reduce impoverishment and catastrophic health expenditure, acknowledging that the current system of health care cannot fully identify and protect the poor [20]. The high degree of awareness and positive perception about health insurance may ensure the expansion of the policy among community people. Health insurance coverage may serve as an important policy tool in promoting health services and in reducing inequities in health care treatment to the marginalized and low income people.

\section{CONCLUSIONS}

Educational level and occupation has influence on the level of awareness and perception about health insurance. Therefore, awareness programme on health insurance needs to be implemented through mass media campaigns.

Author Contributions: Concept and design: BRD, SSG and BKY; statistical analysis: BRD, SPK; writing of the manuscript, BRD, SSG, and DKK; revision and editing the manuscript: BRD, SSG, SPK, DKK and BKY. All authors contributed to all-analysis, interpretation of results, literature review, and revision of the manuscript, and all have read and agreed with the contents of the final manuscript.

Data Availability: Data will be available up on request to corresponding authors after valid region. 


\section{REFERENCES}

1. World Health Statistics. World health statistics 2020: Monitoring health for the SDGs, sustainable development goals. Geneva: World Health Organization. 2020.

2. The Constitution of Nepal. The Constitution of Nepal 2015.

3. Pandey, S. Health and healthcare in Nepal: An analysis of the private and public sector (2018). Electronic Theses and Dissertations. 2009.

4. Kutzin J. Health insurance for the formal sector in Africa. WHO Geneva. 1997.

5. El-Sayed, A. M., Palma, A., Freedman, L. P., \& Kruk, M. E. Does health insurance mitigate inequities in non-communicable disease treatment? Evidence from 48 low- and middle-income countries. Health Policy; 2015, 119(9): 1164-75.

6. Government of Nepal, Department of Health Services. National health insurance policy. Kathmandu: GoN/DoHS. 2013.

7. Health Insurance Board. Nepal Government Health Insurance Board of Nepal. 2021.

8. Government of Nepal. Nepal Health Insurance Act 2017.

9. NHIS. National health insurance scheme annual report. National Health Insurance Scheme Abuja, Nigeria. 2006.
10. Thuan N., Lofgren C., Chuck N., Janlert U., Lindholm L. Household out-of-pocket payments for illness: Evidence from Vietnam. BMC Public Health. 2006;6:283.

11. Preker, A. S., Zweifel, P. and Schellekens, O P. Global marketplace for private health insurance: Strength in numbers. Washington DC: World Bank. 2010.

12. McIntyre D. Learning from experience: Health care financing in low and middle income countries. Global Forum for Health Research, Geneva. 2007.

13. World Health Organization. Closing the health inequalities gap: An international perspective. 2005.

14. Shrestha, M. V., Manandhar, N., Dhimal, M., \& Joshi, S. K. Awareness on social health insurance scheme among locals in Bhaktapur municipality. Journal of Nepal Health Research Council. 2020; 18(48):422-5.

15. Mohammed, S., Sambo, M. N., \& Dong, N. Understanding client satisfaction with a health insurance scheme in Nigeria: factors and enrollees experiences. Health Research Policy and Systems. 2011;9:20.
16. Thapa R., Lamsal S., Badhu A., \& Shrestha, S. Awareness regarding health insurance policy scheme of government of Nepal among local residents of Dharan submetropolitan city. JBPKIHS. 2021;4(1):32-36.

17. Mathur T., Paul U. K., Prasad H. N., \& Das S. C. Understanding perception and factors influencing private voluntary health insurance policy subscription in the Lucknow region. Int J Health Policy Manag. 2015; 4:75-83.

18. Stoermer M., Fuerst F., Rijal K., Bhandari R., Nogier C., Gautam G. S., et al. Review of communitybased health insurance initiatives in Nepal. Kathmandu: Deutsche Gesellschaft für Internationale Zusammenarbeit (GIZ) GmbH. 2012.

19. Nepal Health Sector Strategy 20152020. Government of Nepal, Ministry of Health and Population. 2015 .

20. Mishra, S. R., Khanal, P., Karki, D. K., Kallestrup, P., \& Enemark, U. National health insurance policy in Nepal: Challenges for implementation. Glob Health Action. 2015;8:28763. 